\title{
Preface to the Special Issue on recent advances in the study of Equatorial Plasma Bubbles and Ionospheric Scintillation
}

\author{
Yuichi Otsuka ${ }^{\text {* }}$, Luca Spogli' ${ }^{2}$, S. Tulasi Ram ${ }^{3}$, and GuoZhu Li ${ }^{4}$ \\ ${ }^{1}$ Institute for Space-Earth Environmental Research, Nagoya University, Japan; \\ ${ }^{2}$ Istituto Nazionale di Geofisicae Vulcanologia, Italy; \\ Indian Institute of Geomagnetism, India; \\ ${ }^{4}$ Institute of Geology and Geophysics, Chinese Academy of Sciences, Beijing 100029, China
}

Citation: Otsuka, Y., Spogli, L., Tulasi Ram, S., and Li, G. Z. (2021). Preface to the Special Issue on recent advances in the study of Equatorial Plasma Bubbles and Ionospheric Scintillation. Earth Planet. Phys., 5(5), 365-367. http://doi.org/10.26464/epp2021050

\begin{abstract}
The 2nd Equatorial Plasma Bubble (EPB) workshop, funded by the Institute of Geology and Geophysics, Chinese Academy of Sciences, and the National Natural Science Foundation of China, took place in Beijing, China during September 13-15, 2019. The EPB workshop belongs to a conference series that began in 2016 in Nagoya, Japan at the Institute for Space-Earth Environmental Research, Nagoya University, resulting in a special issue of Progress in Earth and Planetary Science that focused on EPBs. The main goal of the series is to organize in-depth discussion by scientists working on ionospheric irregularities, and solve the scientific challenges in EPB and ionospheric scintillation forecasting. The 2 nd EPB workshop gathered almost 60 scientists from seven countries. A total of 20 invited and contributing papers focusing on ionospheric irregularities and scintillations were presented. Here we briefly comment on 10 papers included in this special issue.
\end{abstract}

Keywords: equatorial plasma bubble; ionospheric irregularity and scintillation; plasma instability; 2nd EPB workshop

Equatorial Plasma Bubbles (EPBs), which are initially generated at the bottomside equatorial $F$ region and then may rise to a few thousand kilometers and extend to low even middle latitudes, can cause rapid amplitude and phase fluctuations of radio signals traversing through them, producing serious ionospheric scintillations and disrupting satellite-based radio links. Considering that the Global Navigation Satellite System (GNSS) has been widely used in various aspects of modern high technology society, it is important to forecast the occurrences of EPB and scintillation, and to mitigate their possible effects. Although numerous studies on EPBs and associated scintillations have been performed, and their climatological behaviors have been well understood, predicting them on a daily basis remains a daunting challenge. In this regard, the EPB workshop series were designed to bring together scientists from the ionosphere community to discuss the current status of our knowledges and sketch what remains to be done if the forecasting of EPBs and scintillation is to be significantly improved.

The present special issue includes ten papers, covering a broad range of topics related to ionospheric irregularities and scintillations, the seeding processes of EPBs, the factors driving the generation of post-sunset and midnight EPBs, the characteristics of EPBs under quiet and disturbed geomagnetic conditions, the in-

Correspondence to: Y. Otsuka, otsuka@isee.nagoya-u.ac.jp

Received 29 AUG 2021; Accepted 06 SEP 2021.

Accepted article online 14 SEP 2021.

(C)2021 by Earth and Planetary Physics. tensity of scintillations and its relationship with the zonal drifts of EPB irregularities, and a review of middle latitude irregularities.

The large-scale wave structure (LSWS) in the bottom side $\mathrm{F}$ region has been regarded as an important precursor condition, seeding the EPBs. By using GNSS-based TEC, ionosonde ionograms, and all-sky imager Ol $630 \mathrm{~nm}$ airglow data over South America, Takahashi et al. (2021) investigated the characteristics of the afternoon-to-evening LSWS in the equatorial ionosphere. They found that the wave fronts they studied were aligned with the solar terminator, extending longer than $1600 \mathrm{~km}$ at low latitude. The propagation direction was mainly toward northeast to southeast, suggesting that the LSWS is effective in seeding EPBs. The LSWS exhibits two different vertical phase propagation modes, in-phase and downward phase; the former may be due to oscillation of the local polarization electric field, whereas the latter may be generated by local atmospheric gravity waves. During the period September to December, EPBs following an occurrence of LSWS were observed frequently suggesting that the effectiveness of the LSWS in triggering EPBs must be due to its seasonal variations, which could be a part of medium-scale traveling ionospheric disturbances (MSTIDs).

Using data collected during the June solstices of 2010-2014 by the $47 \mathrm{MHz}$ Equatorial Atmosphere Radar (EAR) at Kototabang, Indonesia, Ajith et al. (2021) investigated the influence of the solar activity on the occurrence of midnight EPBs. They found that occurrences of midnight $F$ region irregularities were at a maximum during the low solar activity year 2010 and decreased with increasing solar activity. When solar activity was low, the $F$ layer was 
elevated during the midnight hours. They further analyzed the $E \times$ $B$ drift velocity, together with the physics-based SAMI2 model, to estimate the Rayleigh-Taylor (R-T) instability growth rate. A higher growth rate was observed during the midnight hours of low solar activity years, which corresponds to the high EPB occurrence observed by EAR. The factors responsible for conditions favorable to the generation of summer midnight EPBs were discussed in light of the elevated $F$ layer due to the weak westward electric field in the presence of equatorward neutral wind and the possible seeding of R-T instability by MSTIDs.

The pre-reversal enhancement of the eastward electric field (PRE) near sunset plays an important role in the generation of EPBs. Using observations from the ionosondes at Chumphon (dip lat. $3.0^{\circ} \mathrm{N}$ ), Bac Lieu (dip lat. $1.7^{\circ} \mathrm{N}$ ) and Cebu (dip lat. $3.0^{\circ} \mathrm{N}$ ), the magnetometers at Phuket (dip lat. $0.1^{\circ} \mathrm{S}$ ) and Kototabang (dip lat. $10.3^{\circ} \mathrm{S}$ ), and the Gravity Field and Steady-State Ocean Circulation Explorer (GOCE) satellite, Abadi et al. (2021) investigated the influences of eastward neutral wind and equatorial electrojet (EEJ) on the PRE strength. They found that the PRE is positively correlated with the intensity of eastward neutral wind and EEJ. It suggests that both eastward neutral wind and EEJ near sunset are involved in the PRE mechanism.

Using Ol $630.0 \mathrm{~nm}$ airglow observations at Bom Jesus da Lapa $\left(13.3^{\circ} \mathrm{S}, 43.5^{\circ} \mathrm{W}\right)$, Wrasse et al. (2021) investigated the interaction between EPBs and the MSTID over the Northeast region of Brazil. An EPB was observed propagating eastward, in an apparent fossil stage, until it interacted with a dark band electrified MSTID (eMSTID) on the night of September 16 to 17, 2020. After the interaction, four EPBs merged, followed by an abrupt southward development and bifurcations. It was suggested that an eastward polarization electric field, induced by the dark band eMSTID, forced the EPB to drift upward, growing latitudinally along the magnetic field lines and then bifurcating. Partial inhibition of EPB by MSTID occurs after the bubble intensifies and bifurcates.

Bifurcated EPB structures appear at times as an EPB evolves. Wu K et al. (2021) investigated the statistical occurrence characteristics of branching structure of EPBs (BSEPBs) using seven-year (2012-2018) of data from the all-sky airglow imagers at Fuke $\left(19.5^{\circ} \mathrm{N}, 109.1^{\circ} \mathrm{E}\right)$ and Qujing $\left(25^{\circ} \mathrm{N}, 104^{\circ} \mathrm{E}\right)$. They found a high incidence of Branching structure (BS) in EPB cases. Most BSEPBs were characterized by two or three branches. The BSEPBs occurrence was positively related to solar and geomagnetic activity. Multi-branching appeared only in the solar maximum. Most of the BSEPBs began to appear between 21:00 and 22:00 LT.

Under geomagnetically disturbed conditions, the generation and evolution of EPBs get more complex. Huang FQ et al. (2021) investigated the variations of EPBs in the East-Asian sector during a strong geomagnetic storm in October 2016, using observation from the Beidou geostationary satellite receivers, the Swarm constellation, and ground-based ionosondes; they found that postsunset EPBs were enhanced during the main phase and suppressed throughout the recovery phase. Rare sunrise EPBs were triggered on 14 October 2016 in the main phase rather than during the recovery phase. They further analyzed the minimum virtual height of the $\mathrm{F}$ layer $\left(h^{\prime} \mathrm{F}\right)$ at Sanya $\left(18.3^{\circ} \mathrm{N}, 109.6^{\circ} \mathrm{E}\right)$. The $h^{\prime} \mathrm{F}$ was enhanced in the main phase and declined during the recovery phase, compared with the values at pre- and post-storm. It was suggested that the enhanced frequency of EPBs at nighttime and sunrise during the main phase, and the absence of nighttime EPBs for many days during the recovery phase, could be associated with storm-time electric field changes.

Otsuka et al. (2021) investigated temporal variations in the horizontal two-dimensional distribution of total electron content (TEC) during the geomagnetic storm of May 2017, by analyzing GNSS TEC data collected in Japan. They found that TEC depletions observed at about 05:00 LT on 29 May 2017 extended up to approximately $38^{\circ} \mathrm{N}$ over Japan along the meridional direction. The TEC depletions appeared sequentially over Japan for approximately 8 hours in sunlit conditions. At 06:00 on 29 May, when the plasma depletions first appeared over Japan, the background TEC was enhanced to approximately $17 \mathrm{TECU}$, and then decreased to approximately $80 \%$ of the TEC typical of magnetically quiet conditions. By using the SAMI2 model, they evaluated how plasma production and ambipolar diffusion along the magnetic field may affect the rate of plasma depletion disappearance. They concluded that the temporal variation of background plasma density in the ionosphere was responsible for the unusual persistence of these plasma depletions in daytime.

Sun LC et al. (2021) investigated the evolution of an EPB event at low latitudes on 6 December 2015, using multiple ground-based instruments in middle and low latitudes of China. The EPB depletions were observed surging poleward from $\sim 10^{\circ}$ to $19^{\circ}$ magnetic latitudes two hours before the local midnight after a short stay ( 3 hours) near $10^{\circ}$ magnetic latitude. Bifurcations were evolving rapidly from the tips of depletions as the depletions extended poleward. Two brightness blobs were gradually generated as the EPB depletions accelerated. It was suggested that an enhanced equatorward wind most likely induced by a substorm could have initiated the R-T instability and destabilized the EPB depletions. Smaller-scale bifurcations could have evolved rapidly from the secondary $E \times B$ instability as the substorm-inducing southwestward wind blew through. During the growth phase of the EPB depletions, a westward polarization electric field may have compressed plasma downward, inducing the brightness blobs in the bottomside ionosphere. An enhanced poleward wind associated with a passing-by brightness wave may have transported plasma to fill the airglow depletions, which finally evolved into brightness airglow structures.

Cesaroni et al. (2021) studied the zonal drift velocity of small-scale ionospheric irregularities at low latitude by applying the spacedreveiver technique to measurements collected during the period September 2013-February 2014 by two GNSS reveivers for scintillation monitoring installed along the magnetic parallel passing through Presidente Prudente (Brazil, magnetic latitude $12.8^{\circ} \mathrm{S}$ ). They found that the hourly average of the velocity increased up to $135 \mathrm{~m} / \mathrm{s}$ right after the local sunset and then smoothly decreased in the next hours, in agreement with independent estimations of the velocity made by the incoherent scatter radar at Jicamarca (magnetic latitude $0.1^{\circ} \mathrm{N}$ ), and by the Boa Vista ionosonde (magnetic latitude $12.0^{\circ} \mathrm{N}$ ). They further investigated the relationship of zonal drifts with the percentage occurrence of amplitude scintillation. It was found that the scintillation occurrence is exponentially dependent on the zonal velocity of the irregularities that 
cause it.

Liu Y et al. (2021) briefly reviews middle latitude E- and F-region irregularities. At middle latitudes, strong Es appear mainly during daytime in summer hemispheres, and are formed primarily through the neutral wind shear. The $E$ region field-aligned irregularity (FAI) frequently occurs after sunset in summer hemispheres. There is a close relationship between Es and the E region FAl. Strong neutral wind shear, steep Es plasma density gradient, and polarization electric field are significant factors affecting the formation of $\mathrm{E}$ region $\mathrm{FAI}$. In the nighttime $\mathrm{F}$ region, a strong connection exists across different scale size irregularities, such as spread F, MSTID, and FAI. The different scale size irregularities are generally attributed to the Perkins instability and subsequent gradient drift instability. Nighttime MSTIDs can further evolve into smallscale structures through a nonlinear cascade process when a steep plasma density gradient exists at the bottom of the $\mathrm{F}$ region. The effects of ionospheric electrodynamic coupling processes, including ionospheric E-F region coupling and inter-hemispheric coupling, on the generation of ionospheric irregularities, are prominent due to the significant dip angle and equipotentiality of magnetic field lines in the mid-latitude ionosphere. Polarization electric fields can map to different ionospheric regions and excite plasma instabilities, producing irregularities.

Great efforts have been made to improve the understanding of EPBs and scintillation. We hope you enjoy reading these articles. To be frank, much remains to be done before the day-to-day variability of EPBs can be understood sufficiently well for their occurrence to be forecast reliably on a daily basis (e.g., Abdu, 2019, and the references therein). In the equatorial and low latitude regions of South America and East and South East Asian sectors, dense observational networks and large facilities for observing EPBs, scintillations, and background ionosphere have been deployed in recent years or are now being installed (e.g., Maruyama et al., 2007; Valladares and Chau, 2012; Patra et al., 2015; Tsuda et al., 2016; Povero et al., 2017; Li GZ et al., 2021). Based on this enhanced observing capability, it is expected that further progress in the forecasting of EPBs and scintillation will be made soon.

We very much welcome you to attend the $3^{\text {rd }}$ EPB workshop, to be announced in the near future.

\section{Acknowledgments}

The guest editors wish to thank all the authors and the reviewers (Drs. Ercha Aa, Prayitno Abadi, Lucilla Alfonsi, Nanan Balan, Tam Dao, Narayanan V. Lakshmi, George Zhizhao Liu, Guanyi Ma, Daniel Okoh, Ashik Paul, Fabiano Rodrigues, Susumu Saito, Hisao Takahashi, Smitha V Thampi, Haiyong Xie, and Tatsuhiro Yokoyama) for their efforts, as well as the EPP copyeditor Mr. David Eisenman who helped us in the editorial work. Li acknowledges the support from National Natural Science Foundation of China (42020104002).

\section{References}

Abadi, P., Otsuka, Y., Liu, H. X., Hozumi, K., Martinigrum, D. R., Jamjareegulgarn, P., Thanh, L. T., and Otadoy, R. (2021). Roles of thermospheric neutral wind and equatorial electrojet in pre-reversal enhancement, deduced from observations in Southeast Asia. Earth Planet. Phys., 5(5), 387-396. https://doi.org/10.26464/epp2021049

Abdu, M. A. (2019). Day-to-day and short-term variabilities in the equatorial plasma bubble/spread F irregularity seeding and development. Prog. Earth Planet. Sci., 6(1), 11. https://doi.org/10.1186/s40645-019-0258-1

Ajith, K. K., Ram, S. T., Li, G. Z., Yamamoto, M., Hozumi, K., Yatimi, C. Y., and Supnithi, P. (2021). On the solar activity dependence of midnight equatorial plasma bubbles during June solstice periods. Earth Planet. Phys., 5(5), 378-386. https://doi.org/10.26464/epp2021039

Cesaroni, C., Spogli, L., Franceschi, G. D., Damaceno, J. G., Grzesiak, M., Vani, B., Monico, J. F. G., Romano, V., Alfonsi L., and Cafaro, M. (2021). A measure of ionospheric irregularities: zonal velocity and its implications for L-band scintillation at low-latitudes. Earth Planet. Phys., 5(5), 450-461.

https://doi.org/10.26464/epp2021042

Huang, F. Q., Lei, J. H., Xiong, C., Zhong, J. H., and Li, G. Z. (2021). Observations of equatorial plasma bubbles during the geomagnetic storm of October 2016. Earth Planet. Phys., 5(5), 416-426. https://doi.org/10.26464/epp2021043

Li, G. Z., Ning, B. Q., Otsuka, Y., Abdu, M. A., Abadi, P., Liu, Z. Z., Spogli, L., and Wan, W. X. (2021). Challenges to equatorial plasma bubble and ionospheric scintillation short-term forecasting and future aspects in east and southeast Asia. Surv. Geophys., 42(1), 201-238. https://doi.org/10.1007/s10712-02009613-5

Liu, Y., Zhou, C., Xu, T., Tang, Q., Deng, Z. X., Chen, G. Y., and Wang, Z. K. (2021). Review of ionospheric irregularities and ionospheric electrodynamic coupling in the middle latitude region. Earth Planet. Phys., 5(5), 462-482. https://doi.org/10.26464/epp2021025

Maruyama, T., Kawamura, M., Saito, S., Nozaki, K., Kato, H., Hemmakorn, N., Boonchuk, T., Komolmis, T., and Ha Duyen, C. (2007). Low latitude ionosphere-thermosphere dynamics studies with inosonde chain in Southeast Asia. Ann. Geophys., 25(7), 1569-1577. https://doi.org/10.5194/angeo-25-1569-2007

Otsuka, Y., Shinbori, A., Sori, T., Tsugawa, T., Nishioka, M., and Huba, J. D. (2021). Plasma depletions lasting into daytime during the recovery phase of a geomagnetic storm in May 2017: Analysis and simulation of GPS total electron content observations. Earth Planet. Phys., 5(5), 427-434. https://doi.org/10.26464/epp2021046

Patra, A. K., Srinivasulu, P., Chaitanya, P. P., Rao, M. D., and Jayaraman, A. (2015). First results on low-latitude $E$ and $F$ region irregularities obtained using the Gadanki lonospheric Radar Interferometer. J. Geophys. Res.: Space Phys., 119(12), 10276-10293. https://doi.org/10.1002/2014JA020604

Povero, G., Alfonsi, L., Spogli, L., Di Mauro, D., Cesaroni, C., Dovis, F., Romero, R., Abadi, P., Le Huy, M., ... Floury, N. (2017). lonosphere monitoring in South East Asia in the ERICA study. Navigation, 64(2), 273-287. https://doi.org/10.1002/navi.194

Sun, L. C., Xu, J. Y., Zhu, Y. J., Yuan, W., and Zhao, X. K. (2021). Case study of an Equatorial Plasma Bubble Event investigated by multiple ground-based instruments at low latitudes over China. Earth Planet. Phys., 5(5), 435-449. https://doi.org/10.26464/epp2021048

Takahashi, H., Essien, P., Figueiredo, C. A. O. B., Wrasse, C. M., Barros, D., Abdu, M. A., Otsuka, Y., Shiokawa, K., and Li, G. Z. (2021). Multi-instrument study of longitudinal wave structures for plasma bubble seeding in the equatorial ionosphere. Earth Planet. Phys., 5(5), 368-377. https://doi.org/10.26464/epp2021047

Tsuda, T., Yamamoto, M., Hashiguchi, H., Shiokawa, K., Ogawa, Y., Nozawa, S., Miyaoka, H., and Yoshikawa, A. (2016). A proposal on the study of solarterrestrial coupling processes with atmospheric radars and ground-based observation network. Radio Sci., 51(9), 1587-1599. https://doi.org/10.1002/2016RS006035

Valladares, C. E., and Chau, J. L. (2012). The low-latitude ionosphere sensor network: initial results. Radio Sci., 47(4), RSOL17. https://doi.org/10.1029/2011RS004978

Wrasse, C. M., Figueiredo, C. A. O. B., Barros, D., Takahashi, H., Carrasco, A. J., Vital, L. F. R., Rezende, L. C. A., Egito, F., Rosa, G. M., and Sampaio, A. H. R. (2021). Interaction between Equatorial Plasma Bubbles and a Medium-Scale Traveling lonospheric Disturbance, observed by OI $630 \mathrm{~nm}$ airglow imaging at Bom Jesus de Lapa, Brazil. Earth Planet. Phys., 5(5), 397-406. https://doi.org/10.26464/epp2021045

Wu, K., Xu, J. Y., Zhu, Y. J., and Yuan, W. (2021). Occurrence characteristics of branching structures in equatorial plasma bubbles: a statistical study based on all-sky imagers in China. Earth Planet. Phys., 5(5), 407-415. https://doi.org/10.26464/epp2021044 